\title{
Adipose tissue distribution and risk of metabolic disease: does thiazolidinedione-induced adipose tissue redistribution provide a clue to the answer?
}

\author{
X. Yang • U. Smith
}

Received: 28 November 2006 / Accepted: 26 January 2007 / Published online: 29 March 2007

(C) Springer-Verlag 2007

\begin{abstract}
The relative effect of visceral and subcutaneous obesity on the risk of chronic metabolic disease has been a matter of long-term dispute. While ample data support either of the fat depots being causative or associative, valid argument for one depot often automatically belittles the other. Paradigms such as the visceral/portal hypothesis and the acquired lipodystrophy/ectopic fat storage and endocrine hypothesis have been proposed. Nevertheless, neither hypothesis alone explains the entire pathophysiological setting. Treatment of diabetes with thiazolidinediones selectively increases fat partitioning to the subcutaneous adipose depot but does not change visceral fat accumulation. This is in contrast to the preferential visceral fat mobilisation by diet and exercise. Surgical removal of visceral or subcutaneous adipose tissue yields relatively long-lasting metabolic improvement only when combined with procedures that ameliorate adipose tissue cell composition. These studies illustrate that human adipose tissue in different anatomic locations does not work in isolation, and that there is a best-fit relationship in terms of volume and function among different fat depots that needs to be met to maintain the systemic energy balance and to prevent the complications related to obesity.
\end{abstract}

\section{Yang $\cdot$ U. Smith}

Centre of Excellence for Metabolic and Cardiovascular Research/

The Lundberg Laboratory for Diabetes Research, Department of Molecular and Clinical Medicine,

Sahlgrenska University Hospital,

Gothenburg, Sweden

U. Smith $(\square)$

The Lundberg Laboratory for Diabetes Research,

Department of Molecular and Clinical Medicine,

Sahlgrenska University Hospital, Gothenburg University,

SE-413 45 Gothenburg, Sweden

e-mail: ulf.smith@medic.gu.se
Keywords Adipocytokines · Adipose tissue cell composition · Adipose tissue distribution - Diet and exercise intervention · Insulin resistance · Lipolysis .

Thiazolidinediones · Type 2 diabetes · Visceral and subcutaneous fat depot

$\begin{array}{ll}\text { Abbreviations } \\ \text { AMPK } & \text { AMP-activated protein kinase } \\ \text { ATGL } & \text { adipose triacylglycerol lipase } \\ \text { C/EBP } & \text { CCAAT/enhancer binding protein } \\ \text { CT } & \text { computed tomography } \\ \text { HSL } & \text { hormone-sensitive lipase } \\ \text { L4-L5 } & \text { at the level of the 4th and 5th lumbar vertebrae } \\ \text { LPL } & \text { lipoprotein lipase } \\ \text { MHO } & \text { metabolically healthy but obese } \\ \text { MONW } & \text { metabolically obese but normal weight } \\ \text { MRI } & \text { magnetic resonance imaging } \\ \text { PKA } & \text { protein kinase A } \\ \text { PPAR } & \text { peroxisome proliferator-activated receptor } \\ \text { RXR } & \text { retinoid X receptor } \\ \text { TZD } & \text { thiazolidinedione }\end{array}$

\section{Introduction}

The rapidly growing prevalence of obesity in affluent countries in the late twentieth century is a predictable outcome of modern industrialisation, which has led to abundant food supply and substantially reduced daily physical exertion. In evolutionary terms, a lifestyle change in which energy intake continuously exceeds expenditure is in direct conflict to the evolved human 'thrifty genotype' that promotes energy storage as triacylglycerol in adipose cells to meet the demand in times of need. This predispo- 
sition to excess body fat gain or to obesity in the human population may be further accentuated by the improved life expectancy that has contributed to the significant increases in morbidity and mortality associated with the noncommunicable diseases that increase with age, including type 2 diabetes and atherosclerosis.

The relationship between body fat accumulation and the risk of developing chronic complex metabolic diseases is well recognised, albeit not fully understood. A large epidemiological survey conducted from 1976-1980 on 11,864 men and women clearly showed that people with a BMI of $28 \mathrm{~kg} / \mathrm{m}^{2}$ or higher have a significantly increased risk of developing type 2 diabetes, hyperlipidaemia and hypertension $[1,2]$. Nevertheless, the level of risk differs among obese individuals; approximately $20 \%$ of people who meet the criteria for obesity are apparently insulin sensitive and metabolically normal, despite having large amounts of body fat. These individuals have been categorised as metabolically healthy but obese (MHO) subjects [3]. In contrast, there have also been reports that a considerable number of people, about $18 \%$ of the general population, are metabolically obese but have a normal body weight (MONW), i.e. they have a normal BMI or may be slightly overweight, but display several of the metabolic abnormalities associated with the metabolic syndrome [3]. Moreover, patients suffering from the lipodystrophy syndrome, which results in a partial to nearly total body fat loss, often have severely impaired insulin action and distorted metabolic profiles [4]. These findings raise the question: What is the relationship between body fat accumulation and the metabolic characteristics of an individual, given that the same metabolic disturbances develop in all these conditions, which feature diverse amounts of total body fat?

Metabolic disturbances are associated with diverse amounts of total body fat.

\section{Adipose tissue between-depot issues}

The idea that it is the distribution rather than the total amount of body fat that affects the risk of chronic disease was first suggested by the French physician Jean Vague more than 50 years ago, when he observed that people with upper-body (android type) fat accumulation were more prone to the development of diabetes, gout and atherosclerosis than people with lower-body (gynoid type) obesity. Several large epidemiological investigations performed in Sweden and the United States in the early 1980s, using skinfold thickness, waist circumference or WHR as surrogate markers of truncal fatness, confirmed the association between abdominal (upper-body or central) obesity and the risk of cardiovascular disease and diabetes $[1,2]$.
While the anthropometrical measurements do not distinguish between intra-abdominal and abdominal subcutaneous fat accumulation, soft-tissue composition analyses of the abdominal region, using cross-sectional computed tomography (CT) scans or magnetic resonance imaging (MRI) at the level of the 4th and 5th lumbar vertebrae (L4-L5, or umbilicus), have revealed increased abdominal visceral fat accumulation as a critical characteristic that distinguishes MHO subjects from obese people with metabolic disorders and from MONW individuals [5]. Visceral obesity has since been reproducibly implicated as an independent risk factor for insulin resistance and glucose intolerance, which predict type 2 diabetes and cardiovascular disease in different ethnic populations [1, 2]. One of the hypotheses proposed to explain the link between visceral obesity and the chronic complex metabolic diseases is the visceral/portal hypothesis, in which: (1) an increased hepatic uptake of the 'first pass' of NEFAs released from visceral fat lipolysis into the portal vein may reduce the hepatic extraction of insulin and thus impair insulin-induced suppression of hepatic gluconeogenesis, leading to increased endogenous glucose production; (2) an increased hepatic lipase activity may remove lipids from LDL and HDL, which, in combination with the decreased degradation of apolipoprotein $\mathrm{B}$ and the increased esterification of NEFAs, results in the increased synthesis and secretion of VLDL and smaller, denser LDL and HDL particles into the systemic circulation, distorting the circulating lipid profile; and (3) an increased systemic NEFA flux may impair insulin action in skeletal muscle and other key tissues via malonyl-CoA/acetyl-CoA carboxylase $\beta$ fuel-sensing and regulation mechanisms $[1,2,6]$.

The visceral/portal hypothesis is mainly based on a possible high rate of visceral fat lipolysis per unit mass, i.e. the larger the visceral fat depot, the greater the NEFA release in visceral obesity, and these NEFAs from the portal circulation may potentially add to the NEFAs in the hepatic artery. However, clinical studies of NEFA kinetics do not support this hypothesis $[1,7]$. It has been reported that, in effect, post-absorptive NEFA levels are not different between obese women with a visceral adipose tissue area of $\geq 65 \mathrm{~cm}^{2}$ and those with an area of $\geq 65 \mathrm{~cm}^{2}$, as measured by $\mathrm{CT}$ at the level of L4-L5 [1, 2]. In addition, obese men with a visceral fat area of $\geq 130 \mathrm{~cm}^{2}$ have normal fasting plasma NEFA levels, and the increased postprandial NEFA concentrations in these subjects appear to be related to impaired triacylglycerol clearance [1, 2]. Furthermore, a recent study that assessed systemic and splanchnic NEFA kinetics, using a technically demanding catheter and tracer method combined with mathematical modelling, has shown that, although visceral/portal NEFA flux increases with increasing amounts of visceral fat, its actual 
contribution to the total NEFAs in the systemic circulation is small-generally less than $5 \%$. The relative contribution of visceral lipolysis to the total amount of NEFAs delivered to the liver varies substantially among subjects, and can range from $0 \%$ to $45 \%$ in people with a visceral fat area of $\sim 150 \mathrm{~cm}^{2}$, as measured by CT at L2-L3, and in extreme cases, subjects who have large amounts $\left(\sim 300 \mathrm{~cm}^{2}\right)$ of visceral fat display a lower visceral NEFA release than subjects with a visceral adipose tissue area of $10 \mathrm{~cm}^{2}$ [7]. These data show that, in practice, it is difficult to estimate an individual's visceral/portal NEFA flux by analysing his/her body composition and body fat distribution. The same study reported that, while obesity increases both splanchnic and leg NEFA release and uptake, obese men show a lower upper-body, non-splanchnic NEFA release than the lean control subjects, despite having large amounts of abdominal subcutaneous fat. This finding may indicate a potential buffering effect of subcutaneous adipose tissue on the high rate of visceral lipolysis in these obese male subjects [7, 8]. Apart from NEFA metabolism, there remains considerable metabolic heterogeneity among people with similar amounts of visceral adipose tissue. In addition, in many obese or type 2 diabetic patients, the presence and severity of metabolic disturbances are clearly contingent on subcutaneous rather than on visceral fat accumulation, although the visceral fat mass of the patients has been large $[1,2]$. These studies collectively suggest that visceral lipolysis alone cannot sufficiently explain systemic, particularly extra-hepatic, insulin resistance, and other cooperative mechanisms must be involved.

Additional paradigms concerning adipose cell development, adipose tissue endocrine function, and ectopic fat accumulation have been proposed. The acquired lipodystrophy/ectopic fat storage hypothesis and the endocrine paradigm [9] postulate that a failure of adipose cell proliferation, which renders the adipose tissue incapable of expanding to accommodate excess energy, results in ectopic fat storage in the liver and skeletal muscle. Additionally, impaired adipocytokine production as a result of impaired adipogenesis may inhibit leptin- and adiponectin-activated AMP-activated protein kinase (AMPK)/ malonyl CoA signalling in the liver and muscle, and thus prevent the ectopically stored fat from being oxidised, both of which can promote insulin resistance.

Hypotheses claiming that either visceral or subcutaneous adipose tissue depots play a causative role in the pathogenesis of chronic metabolic diseases have been proposed and have been supported by ample clinical and laboratory data.

\section{Biological differences between visceral and subcutaneous adipose tissue}

Upper-body (central) fat refers to the abdominal subcutaneous fat depot located immediately beneath the skin and on top of the abdominal musculature in the upper abdominal region, and the visceral depot in the abdominal cavity. The subcutaneous depot in this region is compartmentalised into superficial and deep layers by a fascia, fascia superficialis, and the two compartments show different relationships with clinical metabolic variables [10]. Visceral fat refers to the intraperitoneal fat composed of the greater and lesser omentum and mesenteric adipose tissue. Visceral fat accounts for approximately $20 \%$ of total body fat in men but only $6 \%$ in pre-menopausal women [11]. Lower-body fat is mainly represented by subcutaneous adipose tissue in the gluteal and femoral regions, which are metabolically less active than upper-body adipose tissue and may be protective against the development of metabolic disorders [8]. Sex-related differences in adipose tissue distribution become increasingly less prominent with age $[1,2]$.

While both serve as energy repositories to maintain the systemic equilibrium of energy intake and expenditure, visceral and subcutaneous adipose tissue depots adopt certain constitutive differences in terms of morphology and physiological function that are characteristic of their primary physiological roles $[1,2]$. These differences are maintained through integrated neural/humoral regulation at the levels of lipid mobilisation, adipocytokine production, and adipose cell recruitment and maturation, and may be fundamental in determining the relative effect of the visceral or subcutaneous depot on the systemic homeostasis of metabolism in pathological conditions, as well as the response to diet, exercise or drug treatment [1,2].

NEFA disposal and lipolysis NEFAs originate from the hydrolysis of adipocyte-stored triacylglycerol, in a reaction catalysed by adipose triacylglycerol lipase (ATGL) [12] and hormone-sensitive lipase (HSL), or from triacylglycerolrich lipoproteins, in a reaction catalysed by lipoprotein lipase (LPL). HSL, the rate-limiting enzyme of adipose tissue triacylglycerol hydrolysis, is regulated through reversible phosphorylation. To initiate lipolysis, catecholamines bind to $\beta$-adrenergic receptors to activate adenylyl cyclase, which results in increased intracellular concentrations of cyclic AMP and, thus, activated protein kinase A (PKA). PKA phosphorylates HSL and perilipin, with subsequent translocation of HSL from the cytosol to the lipid droplets [13], leading to the hydrolysis of triacylglycerols. Catecholamine release is increased when there is an increased energy demand (e.g. during physical exercise, trauma or stress), which enhances NEFA efflux from the 
adipose tissue to ensure energy supply to other key tissues. In contrast, as an antagonist of the lipolytic effect of catecholamines, insulin activates phosphodiesterase-3B, which reduces intracellular cAMP levels, leading to reduced PKA and HSL activation. Unlike HSL, ATGL is not regulated by PKA and is mainly involved in basal triacylglycerol hydrolysis [14]. Adipocytes from the visceral adipose depot have a low basal, but a high catecholamine-stimulated, rate of lipolysis compared with cells from abdominal, gluteal, and femoral subcutaneous fat depots. This is consistent with the high number of $\beta$ adrenoceptors and the low number of $\alpha$-adrenoceptors in adipocytes from visceral fat (Table 1). Additionally, in visceral adipose tissue, the anti-lipolytic action of insulin, adenosine and prostaglandins are blunted, which may further augment lipid mobilisation $[1,2]$.

LPL hydrolyses the triacylglycerol carried by chylomicrons and VLDL, and the activity of this enzyme is closely related to the ability of a tissue to incorporate lipoprotein triacylglycerols and NEFAs. Since human adipose tissue derives most of its lipid for storage from dietary triacylglycerol, LPL is a critical regulator of body fat accumulation $[1,2]$. Compared with subcutaneous adipose tissue, visceral adipose tissue has a higher rate of NEFA and triacylglycerol uptake (Table 1). In men, omental adipose tissue takes up approximately $50 \%$ more lipids than abdominal subcutaneous adipose tissue. However, this is not directly correlated with tissue LPL activity. It has been found that visceral and subcutaneous fat depots in men have similar basal levels of LPL activity. Insulin-stimulated LPL activation and acylation-stimulating protein content are higher in subcutaneous than in visceral fat in both men and women (Table 1). Thus, LPL activity may not alone explain the ultimate rate of adipocyte lipid uptake $[1,2]$. Indeed, while LPL-derived NEFAs may either be released into the circulation or taken up and esterified with glycerol 3-phosphate for storage in adipocytes, the relative proportion of NEFAs that undergo each fate is closely dependent on the intracellular HSL activity. In the fasting state, where HSL is active and the intracellular lipolytic rate is high, the uptake of LPLderived NEFAs is low, whereas the opposite is true after a meal $[1,2]$. The visceral lipid store, with its high turnover, may constitute part of the body's buffering capacity during the postprandial lipid flux and protect the tissues from exposure to the diurnal fluctuation of lipids in the circulation [8].

Adipocytokine production Adipose tissue secretes peptide and non-peptide molecules, collectively termed adipocytokines, that function as hormones, regulating the biological activities of neighbouring or distant tissues and organs [15]. Some of the adipocytokines, such as adiponectin, are produced exclusively by adipocytes, whereas others are produced by other cell types in the adipose tissue. Generally, the rate of secretion of most adipocytokines is a function of the amount of fat stored in the adipose cells, a phenomenon that may partly represent a means of adjusting cellular functional activity in a timely manner for the maintenance of optimal adipose tissue physiology and morphology. For example, increased adipose tissue production of TNF $\alpha$ and IL- 6 in obesity may upregulate HSL and downregulate GLUT4 and LPL production and activity, limiting further entry of dietary lipid metabolites into the hypertrophic adipocytes $[1,15]$.

Leptin and adiponectin, the two most studied adipocytokines to date, may exert regulatory effects on the hypothalamus, liver, pancreatic islets and skeletal muscle [15]. Leptin functions as an afferent signal of a negative feedback loop to regulate body weight. A decrease in leptin levels signifies insufficient energy stores, promotes energy intake, reduces energy expenditure, and increases the partitioning of energy to fat, leading to positive energy balance and, consequently, raised leptin levels. An increase in leptin levels induces the opposite effects [16]. Similar to leptin, adiponectin production also responds to systemic energy status. However, while adiposity increases leptin levels, it significantly reduces plasma adiponectin concentrations [17]. Despite their opposing relationships with fat accumulation, adiponectin and leptin both regulate the AMPK pathway to enhance fatty acid oxidation in the target tissues, through either direct action on the AMPK pathway $[18,19]$ or modulation of sympathetic nervous system activity [20].

A number of inflammatory cytokines are secreted by adipose tissue, mostly by the non-adipocytes in the tissue bed [21]. As with adipose tissue NEFA release, one way to consider the primary mechanisms of action of adipose tissue-produced inflammatory cytokines is according to the anatomic location of the fat depot in which the cytokines are produced. Thus, cytokines released by the visceral depot would exert a greater effect on hepatic carbohydrate and lipid metabolism and stimulate hepatic release of inflammatory proteins $[22,23]$, whereas cytokines produced by the subcutaneous depot would mainly affect adipose cell development and function locally [24] and exert systemic effects on, for example, skeletal muscle (Fig. 1). The former may represent the mechanism whereby inflammatory cytokines induce hepatic insulin resistance and chronic systemic inflammation, while the latter diminish adipose tissue storage of lipids, leading to ectopic fat accumulation in the liver and skeletal muscle $[8,9]$.

Levels of leptin expression and secretion are about twoto threefold higher in subcutaneous than in visceral adipose tissue, and are proportional to the amount of triacylglycerol stored in adipose cells [25] and, thus, to adipose cell size $[26,27]$. In contrast, visceral fat secretes more adiponectin 
Table 1 Characteristics of visceral vs subcutaneous adipose tissue

\begin{tabular}{|c|c|c|c|}
\hline & Visceral adipose tissue & Subcutaneous adipose tissue & Reference \\
\hline \multicolumn{4}{|l|}{ Lipogenesis } \\
\hline Basal rate of glucose uptake & ++ & + & {$[63,64]$} \\
\hline Insulin-stimulated glucose uptake & ++ & + & {$[63,65]$} \\
\hline Fatty acid and triacylglycerol uptake & ++ & + & {$[66,67]$} \\
\hline Lipoprotein lipase & $\begin{array}{l}\text { Women }+ \\
\text { Men }+\end{array}$ & $\begin{array}{l}\text { Women }++ \\
\text { Men }+\end{array}$ & {$[1,26,68]$} \\
\hline Insulin-stimulated lipoprotein lipase activity & + & ++ & {$[68]$} \\
\hline Acylation stimulating protein & + & ++ & [1] \\
\hline Lipid synthesis & ++ & + & [69] \\
\hline \multicolumn{4}{|l|}{ Lipolysis } \\
\hline Basal rate of lipolysis & $\begin{array}{l}+ \\
\text { Obesity }++\end{array}$ & $\begin{array}{l}++ \\
\text { Obesity }++\end{array}$ & {$[69-72]$} \\
\hline ATGL & $\begin{array}{l}++ \\
\text { Obesity }++\end{array}$ & $\begin{array}{l}+ \\
\text { Obesity }++\end{array}$ & {$[14]$} \\
\hline HSL content & ++ & + & {$[72]$} \\
\hline HSL activity & + & ++ & {$[70,72]$} \\
\hline Catecholamine-induced lipolysis & +++ & + & {$[67,71,73]$} \\
\hline$\beta$-Adrenoceptor-dependent lipolysis & ++++ & + & [74] \\
\hline$\alpha_{2}$-Adrenocetpor-dependent anti-lipolysis & + & ++ & {$[75,76]$} \\
\hline Anti-lipolytic effect of insulin & + & +++ & {$[67,77]$} \\
\hline \multicolumn{4}{|l|}{ Adipocytokine secretion } \\
\hline Adiponectin secretion & ++ & + & {$[78]$} \\
\hline Leptin secretion & + & ++++ & {$[1,71,79]$} \\
\hline Plasminogen activator inhibitor 1 & ++ & + & {$[1,21,80]$} \\
\hline IL-6 secretion & +++ & + & {$[1,21,81]$} \\
\hline IL-8 secretion & ++++ & + & [82] \\
\hline $\mathrm{TNF} \alpha$ secretion & + & + & {$[1,71,83]$} \\
\hline Angiotensinogen & ++ & + & [1] \\
\hline \multicolumn{4}{|l|}{ Cell development } \\
\hline Proliferation in vitro & + & ++ & {$[84]$} \\
\hline Differentiation in vitro & + & ++ & {$[71,84,85]$} \\
\hline $\operatorname{PPAR} \gamma$ production & + & ++ & {$[1,86,87]$} \\
\hline & Obesity ++ & Obesity + & \\
\hline $\mathrm{C} / \mathrm{EBP} \alpha$ and $\mathrm{RXR} \alpha$ production & + & ++ & {$[86,87]$} \\
\hline Response to TZD treatment in vitro & + & ++ & {$[87,88]$} \\
\hline Response to TZD treatment in vivo & + & ++ & {$[32-38]$} \\
\hline Response to RXR ligands & + & ++ & [87] \\
\hline Adipose cell size & $\begin{array}{l}\text { Omental }+ \\
\text { Mesenteric }+++\end{array}$ & ++ & {$[69,79,89]$} \\
\hline Susceptibility to apoptosis & + & + & {$[90,91]$} \\
\hline \multicolumn{4}{|l|}{ Steroid hormones and receptors } \\
\hline Androgen receptor & ++ & + & [92] \\
\hline Androgen concentration & ++ & + & [93] \\
\hline Glucocorticoid receptor & ++ & + & [94] \\
\hline $11 \beta$-hydroxysteroid dehydrogenase & ++ & + & [95] \\
\hline
\end{tabular}

than subcutaneous fat which, in turn, is more sensitive to insulin and TZDs (Table 1). In addition, visceral fat releases more IL-6, IL-8, plasminogen activator inhibitor 1 and angiotensinogen than subcutaneous fat, while TNF $\alpha$ production is low and shows no consistent depot-related differences (Table 1).

Adipose tissue cell composition The biological activity of an adipocyte changes as its lipid storage increases.
Compared with small adipocytes, large cells are more insulin-resistant and lipolytic, release more inflammatory cytokines and less adiponectin [24, 28], and are more frequently found in people with obesity-related metabolic disorders $[29,30]$. Therefore, adipose tissue cell composition, expressed as the relative number of large adipose cells in a given fat depot, is an important determinant of the metabolic activity and response to environmental changes of that depot. 
Adipose cells are slow-turnover cells. In non-obese people, adipose tissue depot expansion during development from a young age to middle age is mainly the result of a uniform increase in fat cell size [1,2]. In men, there is an increase in adipocyte number in the subcutaneous depot of the abdominal region, while this is not readily seen in women. Unlike obesity developed in childhood or adolescence, which is usually hyperplastic and is commonly seen in MHO subjects [1-3], most adult-onset obesity is related to the hypertrophic expansion of existing adipocytes, i.e. an increase in cell size $[1,2]$. Studies on adipose tissue cellularity have reported that adipocytes become severely insulin-resistant when filled with more than $1 \mu \mathrm{g}$ of lipid per cell, and new adipocyte recruitment normally occurs when the lipid content of the cells reaches $\sim 0.7-0.8 \mu \mathrm{g} / \mathrm{cell}$ [29]. The new cell recruitment may be triggered by a progressively altered secretion of proteins and lipid metabolites from the enlarging adipocytes [24, 28], which could act as signalling molecules on the precursor cells in the adipose tissue bed to initiate and regulate adipogenesis.

Adipose cell recruitment occurs throughout life and overall is regulated by the basal metabolic rate and energy uptake and expenditure. Acquirement of a full adipocyte phenotype entails precursor cell adipose lineage commitment followed by preadipocyte proliferation and differentiation, a process that is characterised by the activation and inactivation of specific genes through the induction of transcription factors such as CCAAT/enhancer binding proteins $(\mathrm{C} / \mathrm{EBPs})$ and peroxisome proliferator-activated receptor $\gamma(\operatorname{PPAR} \gamma)$ [31].

Like other aspects of adipose tissue biology, adipose tissue cellularity is differently regulated in the visceral and subcutaneous depots, and is determined by specific hormone receptor expression, blood supply, innervation and the parasympathetic-sympathetic nervous system activity in the respective depots. The potential of adipogenic precursor cells to perform adipogenesis is also intrinsically different between the two depots. Preadipocytes derived from subcutaneous adipose tissue express higher levels of $\operatorname{PPAR} \gamma, \mathrm{C} / \mathrm{EBP} \alpha$ and retinoid $\mathrm{X}$ receptor $\alpha(\mathrm{RXR} \alpha)$, and more readily proliferate and differentiate in vitro than cells from visceral fat depots (Table 1). In addition, these cells are more sensitive to TZD treatment in vitro, which is consistent with the selective increase in subcutaneous fat mass in patients treated with TZDs [32-39].

Visceral and subcutaneous adipose tissue depots adopt constitutive biological differences that are characteristic of their physiological roles

\section{What do we learn from body fat distribution?}

Human evolution has left its trace on our body fat distribution. Because of the fast intrauterine growth of fetal brain relative to maternal pelvis, human infants are born prematurely and need to be carried and nursed for several years. Evolution has provided a solution to the problem of how to cover the energy demand of both the mother and the child during this period in the form of the lower-body, pelvic-gluteal-femoral fat accumulation in women, which is
Fig. 1 Endocrine effects of cytokines released from visceral or subcutaneous adipose tissue: the cytokines released from visceral depot would primarily alter carbohydrate and lipid metabolism and stimulate production of acute phase response proteins in the liver, whereas the cytokines produced by subcutaneous depot would mainly affect adipose cell development and function locally as well as exert systemic effects on, for example, the skeletal muscle

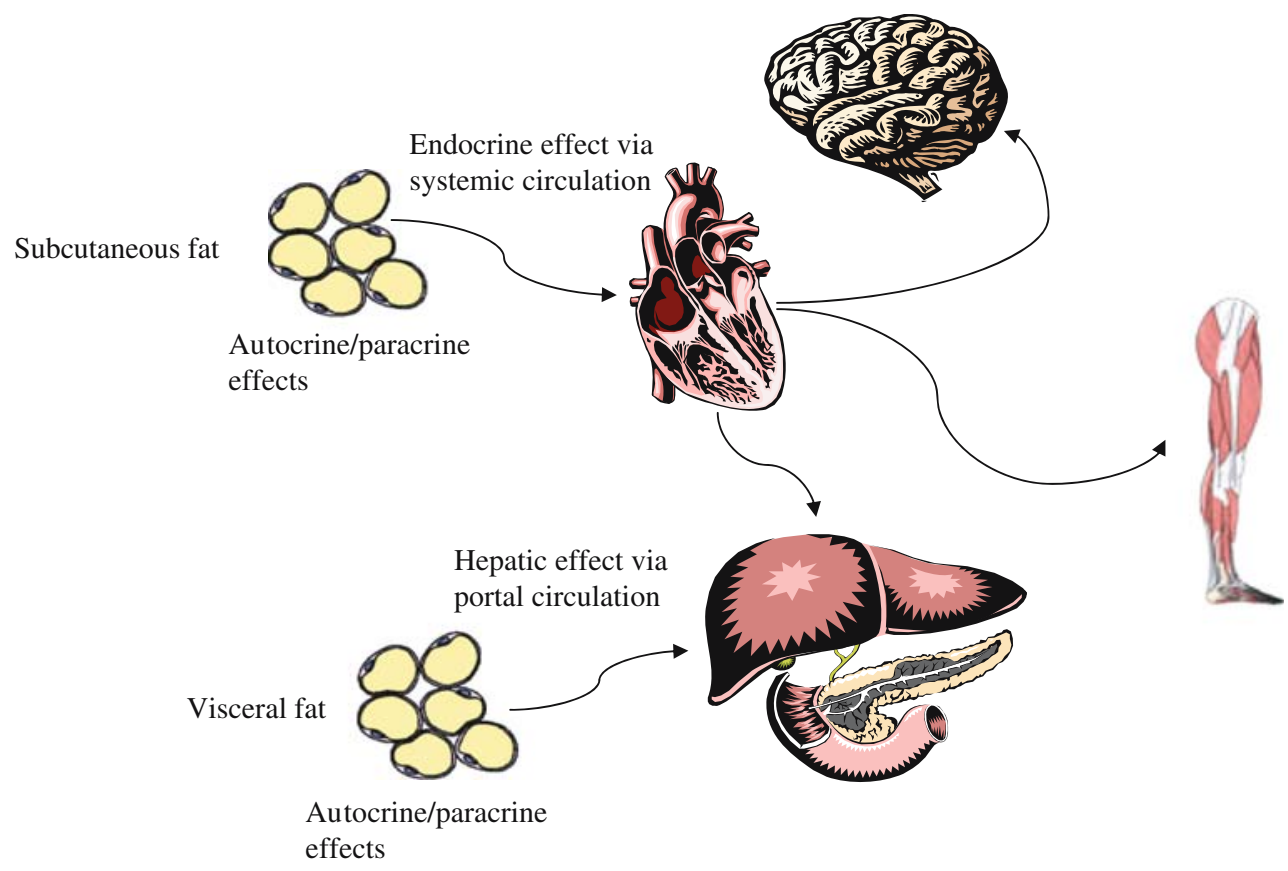


a unique human aspect of the evolution of the animal kingdom. In addition to the sex-related pattern of fat distribution, selective fat partitioning to individual adipose tissue depots, such as the visceral and subcutaneous depots, may occur under a variety of circumstances in which a person's nutritional or endocrine status is changed $[1,2]$.

Visceral adipose tissue area measured from a single MRI scan at the L4-L5 level has a correlation of 0.96 with visceral adipose tissue volumes calculated from multiple (up to 41) scans [11]. Therefore, a single cross-sectional CT or MRI scan at the L4-L5 level is considered to provide an accurate assessment of visceral fat quantity, for which typical values range from $15-260 \mathrm{~cm}^{2}$ [40]. Some studies emphasising visceral fat as a risk factor for metabolic disease have specified threshold values to identify subjects at risk, e.g. a visceral fat area of $\geq 100 \mathrm{~cm}^{2}$ has been used to identify MONW Japanese individuals [41]. However, there have been discrepancies between studies that have used such values, and the differences are not completely explained by ethnic- or sex-related confounders across investigations. For example, in a study on 220 pre- and post-menopausal white women from 18-77 years of age, a visceral fat area of $\geq 110 \mathrm{~cm}^{2}$ was suggested to identify individuals at high risk of cardiovascular and metabolic disease [42], while other studies on 98 post-menopausal Mexican women aged $50-65$ years or on 146 healthy men aged 30 71 years, the value was set at $\geq 117.8 \mathrm{~cm}^{2}$ or $\geq 130 \mathrm{~cm}^{2}$, respectively [43, 44]. Similarly, one intervention study has claimed that a reduction in visceral fat area to $<60 \mathrm{~cm}^{2}$ is necessary to improve risk factors for CHD [45], whereas another study found improvements in plasma HDL-cholesterol levels, the cholesterol:HDL-cholesterol ratio and insulin sensitivity in subjects who reduced their visceral fat to below $110 \mathrm{~cm}^{2}$ compared with those who did not [46]. Furthermore, investigations that stratified subjects according to quantity of visceral fat reported that not all the metabolic alterations observed could be attributed to visceral fat accumulation [47-49].

The visceral to subcutaneous adipose tissue area ratio $(\mathrm{V}$ : $S$ ratio) describes the relative accumulation of visceral and subcutaneous fat without defining absolute quantity of fat in either depot. Use of the ratio value to integrate the size, and hence the potential function of both adipose depots as correlates of systemic metabolism, may mirror the actual human physiology more closely. For example, a human cadaver dissection study on the relationships between visceral, trunk and whole-body adipose tissue weights showed that men and women possessed the same amount of visceral fat $-3.00 \mathrm{~kg}$ in men vs $3.24 \mathrm{~kg}$ in women $(p=$ 0.68) [40] - a result that is difficult to explain given the well-known differences between men and women in terms of adipose tissue distribution and metabolism. However, when the quantity of visceral fat was expressed as a percentage of total body fat in this same study, the difference became apparent: men had $16.8 \%$ of their body fat composed of visceral fat, while the corresponding value in women was only $12.9 \%(p=0.02)$ [40].

Calculation of the V:S ratio as an indicator of body fat distribution using adipose tissue measurements obtained by CT or MRI shows that fat deposition increases in all adipose tissue depots in obesity. However, this increase is not always proportional in the tissues, which results in the subtypes of visceral and subcutaneous, or central and peripheral, obesity. A common treatment regimen for obesity involves restricting daily energy intake and enhancing expenditure, which is normally achieved by prescribing a diet and an exercise programme. Although diet and exercise interventions generally cause more fat loss from the intra-abdominal than the subcutaneous adipose depot [2, 50], variations exist among individuals with regard to how much fat needs to be lost from the two fat depots before statistically significant improvements in insulin sensitivity, lipid profile and other metabolic parameters are observed (Table 2). For example, by comparing the V:S ratios measured before and after an intervention leading to improved systemic carbohydrate and lipid metabolism, it was found that the reduction in the V:S ratio after a given diet or exercise programme might range from $\sim 3-20 \%$ (Table 2). In one study, a 10-week physical exercise programme prescribed to type 2 diabetic patients reduced the V:S ratio by more than $33 \%$, and this was associated with significantly decreased triacylglycerol and increased dehydroepiandrosterone levels [51] (Table 2). In contrast, another study in which metformin was used to treat patients with polycystic ovary syndrome for 12 weeks at a dosage of $500 \mathrm{mg}$ three times daily, showed that the decreased total cholesterol and LDL-cholesterol levels were not accompanied by any significant change in body fat distribution [52] (Table 2).

TZDs are agonists for the nuclear receptor PPAR $\gamma$ and are used to improve glycaemic control, lipid profile and insulin sensitivity. Because of the abundant expression of PPAR $\gamma$ in adipose tissue, it is generally thought that the induction of adipogenesis to recruit new small adipocytes, and thus to improve adipose tissue lipid accommodation and adiponectin secretion, accounts for most of the credible metabolic outcomes of TZD treatment. However, excessive body fat gain following long-term treatment may have detrimental health consequences, particularly in people who are overweight or obese prior to the treatment. Reduced dosages, or combination therapy with metformin, diet or exercise programme, have been reported to be beneficial. Similar to the change in the V:S ratio induced by diet and exercise interventions, variations in the extent of the reduction in the V:S ratio that accompanies improvements in systemic metabolism are also observed in TZD trials 


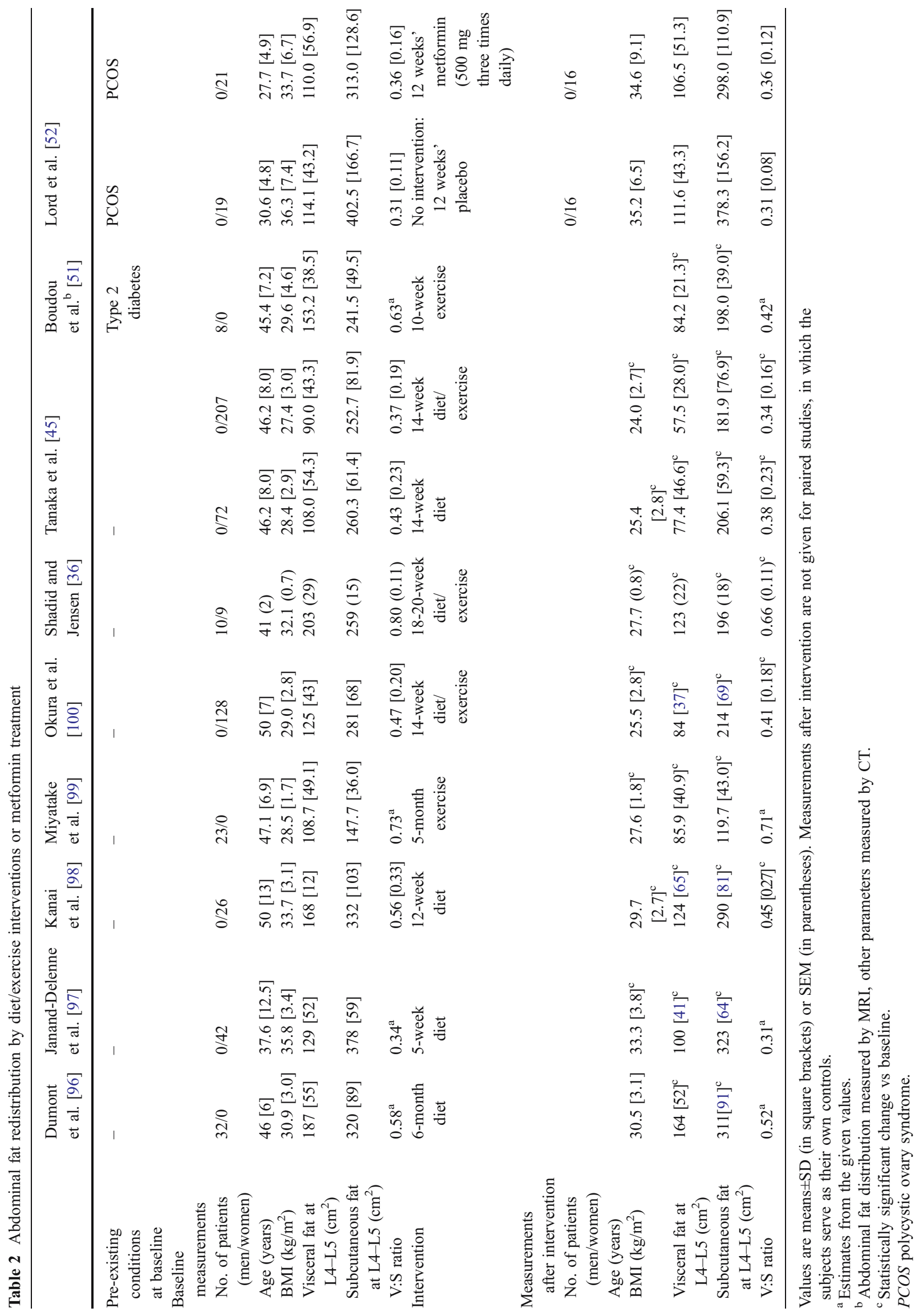




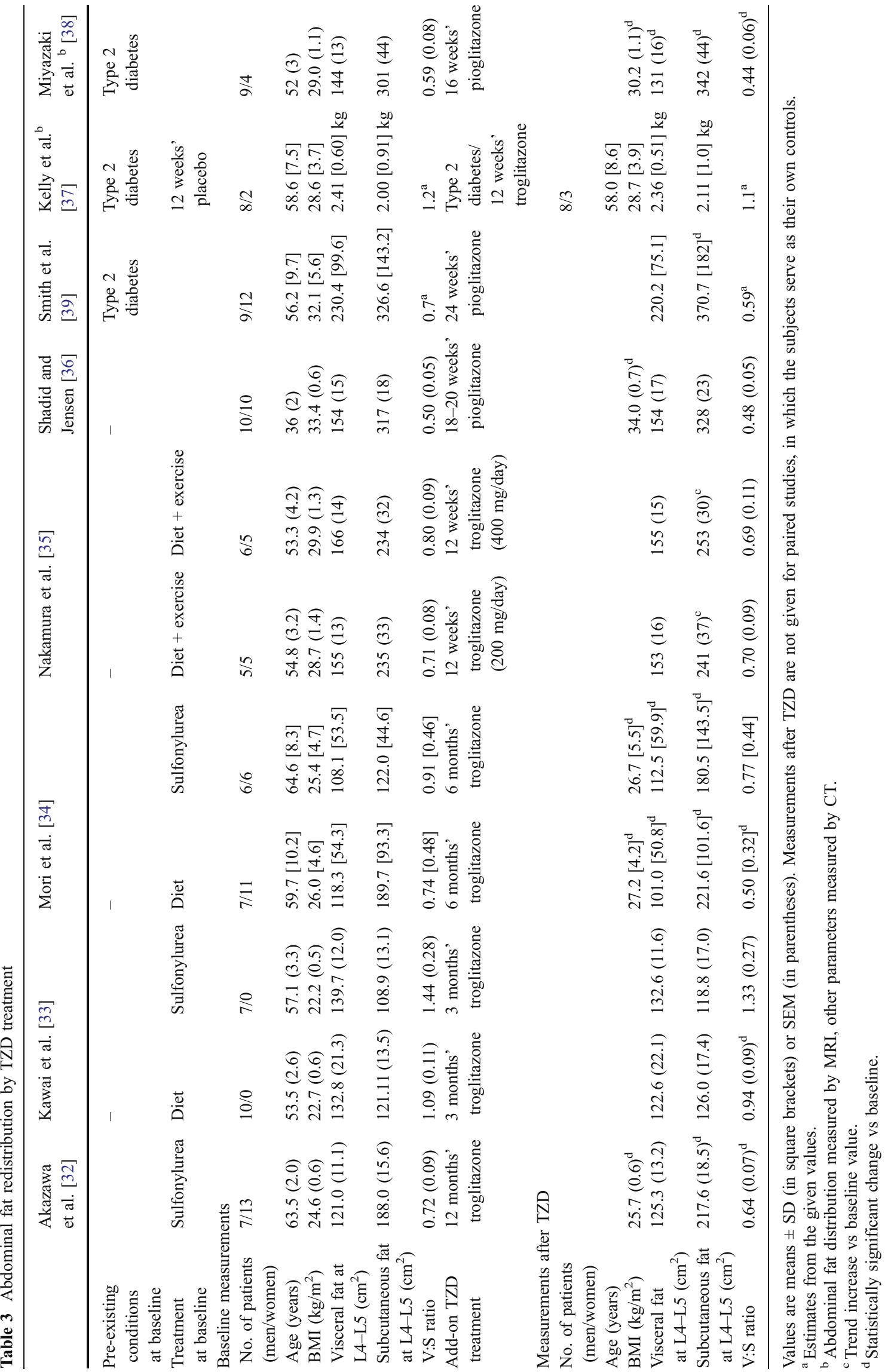


performed by different research groups in different ethnic populations (Table 3). For example, treatment with troglitazone or pioglitazone, either alone or in combination with a diet or exercise programme or with a sulfonylurea, reduced the V:S ratio of the subjects by $\sim 1.5-32 \%$ of the values before the treatment (Table 3 ), which was associated with improved lipid profile and insulin sensitivity. However, in contrast to diet and exercise interventions, where the decreased V:S ratios are the result of mobilisation of the visceral fat (Table 2), the V:S ratio reduction induced by TZD treatment is the result of an increased subcutaneous depot mass with no significant change in visceral fat (Table 3). In one study, which reported a reduction in visceral fat mass after 3 months of treatment with troglitazone, the reduction might have resulted from the combined diet intervention [34] (Table 3). Thus, changing the quantitative relationship between visceral and subcutaneous depots, as indicated by a reduced V:S ratio, may improve systemic metabolism regardless of whether this is achieved through a reduction in visceral or an increase in subcutaneous fat mass. The variations in the size of the reduction in the V:S ratio after diet, exercise or TZD treatment may reflect the quantitative range of the adjustment of either fat depot, in terms of mass and function, required to restore the metabolic balance of the subjects across the studies.

Recently, several attempts have been made to improve the metabolic profile of obese subjects by surgically removing certain quantities of subcutaneous or omental fat [53-58]. However, the outcomes of these studies have been inconsistent. Removal of a large volume of abdominal subcutaneous fat has yielded improved [54-56], unchanged [57] or deteriorated [58] carbohydrate and lipid metabolism. Although promising long-term improvements in fasting plasma glucose and insulin, glucose tolerance and insulin sensitivity have been reported by a study that combined omentectomy with adjustable gastric banding, the metabolic benefits that may have been provided by the reduction of visceral fat may be complemented by the potential reduction in average adipose cell size and, hence the fat mass of all the depots, through the gastric banding [53, 59]. Comparing these studies with the adipose tissue redistribution data from the diet, exercise and TZD studies, the inconsistent metabolic outcomes resulting from the surgical procedures may reflect inter-patient variation in terms of the quantity of fat that needs to be removed (or lost) in order to obtain a best-fit ratio of V:S volume and function.

Adipose tissue redistribution induced by diet, exercise or treatment with TZDs is associated with an increased number of small adipocytes in the adipose tissue, leading to improved adipose tissue cell composition and function. The reduction in average adipose cell size in given depots results from adipocyte lipid depletion by restricting energy intake or enhancing energy expenditure in a diet or an exercise programme. With TZD treatment, this may be achieved by adipose cell recruitment through activation of PPAR $\gamma$ [60]. Although the changes in adipocyte size distribution following TZD treatment vary in human studies $[36,61,62]$, it has been reported that the proportion of small adipocytes increases and the proportion of very large adipocytes decreases after pioglitazone treatment in type 2 diabetic patients [61]. It is conceivable that the surgical removal of adipose tissue may reduce the total release of lipolytic products and inflammatory cytokines from the adipose tissue by reducing the number of hypertrophic adipose cells in obesity. However, in theory, this does not improve the cell composition of the remaining adipose tissue unless the procedure triggers adipogenesis. In this context, the metabolic improvements in the omentectomy/gastric banding study [53] illustrate the significance of comprehensive adjustment of adipose tissue volume and function [53, 59].

Summarising all the studies, if one factor is to be sought to integrate the situations, as Occam's Razor would have argued for, it may be suggested that human adipose tissue in different anatomic locations does not work in isolation, and that, for any given individual, there exists a best-fit relationship in terms of volume and function among different fat depots that needs to be met to maintain the systemic energy balance and prevent the complications related to obesity. Thus, the carbohydrate and lipid metabolism of MHO subjects would remain normal provided their subcutaneous adipose tissue functionally matches the metabolic rate of their visceral adipose tissue, i.e. their subcutaneous tissue is able to take up NEFAs to compensate for the increased visceral lipolysis, while MONW subjects may obtain an improved metabolic profile if the functional relationship between the two depots is properly adjusted.
Human adipose tissue in different anatomic locations does not work in isolation. There is a best-fit relation of volume and function among different fat depots to be met in order to maintain the systemic energy balance and to prevent complications related to obesity

\section{Conclusion}

There have been many discussions about the role of visceral or subcutaneous adipose tissue in the pathogenesis of chronic metabolic diseases. Hypotheses claiming either of the depots to be more causative than the other have been proposed, and are supported by ample clinical and laboratory data. However, in practice, treatments based on either of these hypotheses do not always produce the expected metabolic outcomes, which is particularly evident 
in several recent attempts using surgical procedures to reduce subcutaneous or visceral fat.

Adipose tissue distribution data from the TZD trials, when compared with the data from diet and exercise intervention studies, ascertain that adipose tissue biology in relation to the regulation of systemic metabolism should be considered in integrity; different adipose tissue depots may function differently, yet both co-operatively and compensatorily. Therefore, when contemplating pathogenic mechanisms of obesity-related metabolic disease or prescribing a treatment for the obesity-related syndrome, consciously aiming at an individualized ratio of visceral to subcutaneous adipose tissue volume and functional activity, in addition to general body fat reduction, may prove to be beneficial to obtain intended outcomes.

Acknowledgements The studies referred to from the authors' laboratory are supported by grants from the European Community's FP6 EUGENE2 (LSHM-CT-2004-512013), the Swedish Research Council, the Swedish Diabetes Association, the Sonya Hedenbratt Memorial Fund, the IngaBritt and Arne Lundberg Foundation, the Novo-Nordisk Foundation, the Konrad and Helfrid Johansson's Fund, and the Torsten and Ragnar Söderberg's Foundation.

Duality of interest We declare that we have no duality of interest.

\section{References}

1. Wajchenberg BL (2000) Subcutaneous and visceral adipose tissue: their relation to the metabolic syndrome. Endocr Rev 21:697-738

2. Kissebah AH, Krakower GR (1994) Regional adiposity and morbidity. Physiol Rev 74:761-811

3. Karelis AD, St-Pierre DH, Conus F, Rabasa-Lhoret R, Poehlman ET (2004) Metabolic and body composition factors in subgroups of obesity: what do we know? J Clin Endocrinol Metab 89:2569-2575

4. Reitman ML, Arioglu E, Gavrilova O, Taylor SI (2000) Lipoatrophy revisited. Trends Endocrinol Metab 11:410-416

5. Sims EA (2001) Are there persons who are obese, but metabolically healthy? Metabolism 50:1499-1504

6. Ruderman NB, Saha AK, Vavvas D, Witters LA (1999) Malonyl-CoA, fuel sensing, and insulin resistance. Am J Physiol 276:E1-E18

7. Nielsen S, Guo Z, Johnson CM, Hensrud DD, Jensen MD (2004) Splanchnic lipolysis in human obesity. J Clin Invest 113:15821588

8. Frayn KN (2002) Adipose tissue as a buffer for daily lipid flux. Diabetologia 45:1201-1210

9. Ravussin E, Smith SR (2002) Increased fat intake, impaired fat oxidation, and failure of fat cell proliferation result in ectopic fat storage, insulin resistance, and type 2 diabetes mellitus. Ann N Y Acad Sci 967:363-378

10. Smith SR, Lovejoy JC, Greenway F et al (2001) Contributions of total body fat, abdominal subcutaneous adipose tissue compartments, and visceral adipose tissue to the metabolic complications of obesity. Metabolism 50:425-435

11. Ross R, Leger L, Morris D, de Guise J, Guardo R (1992) Quantification of adipose tissue by MRI: relationship with anthropometric variables. J Appl Physiol 72:787-795
12. Zimmermann R, Strauss JG, Haemmerle G et al (2004) Fat mobilization in adipose tissue is promoted by adipose triglyceride lipase. Science 306:1383-1386

13. Granneman JG, Moore HP, Granneman RL, Greenberg AS, Obin MS, Zhu Z (2007) Analysis of lipolytic protein trafficking and interactions in adipocytes. J Biol Chem 282:5726-5735

14. Mairal A, Langin D, Arner P, Hoffstedt J (2006) Human adipose triglyceride lipase (PNPLA2) is not regulated by obesity and exhibits low in vitro triglyceride hydrolase activity. Diabetologia 49:1629-1636

15. Smith U, Yang X (2005) Adipocytokines and the pathogenesis of the metabolic syndrome. In: Byrne CD, Wild SH (eds) The metabolic syndrome. Wiley, Chichester, pp 239-262

16. Friedman JM (2002) The function of leptin in nutrition, weight, and physiology. Nutr Rev 60:S1-S14; discussion S68-S84

17. Weyer C, Funahashi T, Tanaka S et al (2001) Hypoadiponectinemia in obesity and type 2 diabetes: close association with insulin resistance and hyperinsulinemia. J Clin Endocrinol Metab 86:1930-1935

18. Yamauchi T, Kamon J, Minokoshi Y et al (2002) Adiponectin stimulates glucose utilization and fatty-acid oxidation by activating AMP-activated protein kinase. Nat Med 8:1288-1295

19. Minokoshi Y, Kim YB, Peroni OD et al (2002) Leptin stimulates fatty-acid oxidation by activating AMP-activated protein kinase. Nature 415:339-343

20. Qi Y, Takahashi N, Hileman SM et al (2004) Adiponectin acts in the brain to decrease body weight. Nat Med 10:524-529

21. Fain JN, Madan AK, Hiler ML, Cheema P, Bahouth SW (2004) Comparison of the release of adipokines by adipose tissue, adipose tissue matrix, and adipocytes from visceral and subcutaneous abdominal adipose tissues of obese humans. Endocrinology 145:2273-2282

22. Baumann H, Gauldie J (1990) Regulation of hepatic acute phase plasma protein genes by hepatocyte stimulating factors and other mediators of inflammation. Mol Biol Med 7:147-159

23. Fernandez-Real JM, Vayreda M, Richart C et al (2001) Circulating interleukin 6 levels, blood pressure, and insulin sensitivity in apparently healthy men and women. J Clin Endocrinol Metab 86:1154-1159

24. Sopasakis VR, Sandqvist M, Gustafson B et al (2004) High local concentrations and effects on differentiation implicate interleukin-6 as a paracrine regulator. Obes Res 12:454-460

25. Tritos NA, Mantzoros CS (1997) Leptin: its role in obesity and beyond. Diabetologia 40:1371-1379

26. Montague CT, Prins JB, Sanders L, Digby JE, O'Rahilly S (1997) Depot- and sex-specific differences in human leptin mRNA expression: implications for the control of regional fat distribution. Diabetes 46:342-347

27. Hamilton BS, Paglia D, Kwan AY, Deitel M (1995) Increased obese mRNA expression in omental fat cells from massively obese humans. Nat Med 1:953-956

28. Le Lay S, Krief S, Farnier C et al (2001) Cholesterol, a cell sizedependent signal that regulates glucose metabolism and gene expression in adipocytes. J Biol Chem 276:16904-16910

29. Krotkiewski M, Bjorntorp P, Sjostrom L, Smith U (1983) Impact of obesity on metabolism in men and women. Importance of regional adipose tissue distribution. J Clin Invest 72:1150-1162

30. Weyer C, Foley JE, Bogardus C, Tataranni PA, Pratley RE (2000) Enlarged subcutaneous abdominal adipocyte size, but not obesity itself, predicts type II diabetes independent of insulin resistance. Diabetologia 43:1498-1506

31. Gregoire FM, Smas CM, Sul HS (1998) Understanding adipocyte differentiation. Physiol Rev 78:783-809

32. Akazawa S, Sun F, Ito M, Kawasaki E, Eguchi K (2000) Efficacy of troglitazone on body fat distribution in type 2 diabetes. Diabetes Care 23:1067-1071 
33. Kawai T, Takei I, Oguma Y et al (1999) Effects of troglitazone on fat distribution in the treatment of male type 2 diabetes. Metabolism 48:1102-1107

34. Mori Y, Murakawa Y, Okada K et al (1999) Effect of troglitazone on body fat distribution in type 2 diabetic patients. Diabetes Care 22:908-912

35. Nakamura T, Funahashi T, Yamashita S et al (2001) Thiazolidinedione derivative improves fat distribution and multiple risk factors in subjects with visceral fat accumulation-double-blind placebo-controlled trial. Diabetes Res Clin Pract 54:181-190

36. Shadid S, Jensen MD (2003) Effects of pioglitazone versus diet and exercise on metabolic health and fat distribution in upper body obesity. Diabetes Care 26:3148-3152

37. Kelly IE, Han TS, Walsh K, Lean ME (1999) Effects of a thiazolidinedione compound on body fat and fat distribution of patients with type 2 diabetes. Diabetes Care 22:288-293

38. Miyazaki Y, Mahankali A, Matsuda M et al (2002) Effect of pioglitazone on abdominal fat distribution and insulin sensitivity in type 2 diabetic patients. J Clin Endocrinol Metab 87:2784-2791

39. Smith SR, De Jonge L, Volaufova J, Li Y, Xie H, Bray GA (2005) Effect of pioglitazone on body composition and energy expenditure: a randomized controlled trial. Metabolism 54:24-32

40. Martin AD, Janssens V, Caboor D, Clarys JP, Marfell-Jones MJ (2003) Relationships between visceral, trunk and whole-body adipose tissue weights by cadaver dissection. Ann Hum Biol 30:668-677

41. Fujioka S, Matsuzawa Y, Tokunaga K, Tarui S (1987) Contribution of intra-abdominal fat accumulation to the impairment of glucose and lipid metabolism in human obesity. Metabolism 36:54-59

42. Williams MJ, Hunter GR, Kekes-Szabo T et al (1996) Intraabdominal adipose tissue cut-points related to elevated cardiovascular risk in women. Int J Obes Relat Metab Disord 20:613-617

43. Hunter GR, Snyder SW, Kekes-Szabo T, Nicholson C, Berland L (1994) Intra-abdominal adipose tissue values associated with risk of possessing elevated blood lipids and blood pressure. Obes Res 2:563-568

44. Hernandez-Ono A, Monter-Carreola G, Zamora-Gonzalez J et al (2002) Association of visceral fat with coronary risk factors in a population-based sample of postmenopausal women. Int J Obes Relat Metab Disord 26:33-39

45. Tanaka K, Okura T, Shigematsu R et al (2004) Target value of intraabdominal fat area for improving coronary heart disease risk factors. Obes Res 12:695-703

46. Brochu M, Tchernof A, Turner AN, Ades PA, Poehlman ET (2003) Is there a threshold of visceral fat loss that improves the metabolic profile in obese postmenopausal women? Metabolism 52:599-604

47. Lerario AC, Bosco A, Rocha M et al (1997) Risk factors in obese women, with particular reference to visceral fat component. Diabetes Metab 23:68-74

48. Pascot A, Despres JP, Lemieux I et al (2001) Deterioration of the metabolic risk profile in women. Respective contributions of impaired glucose tolerance and visceral fat accumulation. Diabetes Care 24:902-908

49. Ribeiro-Filho FF, Faria AN, Kohlmann NE, Zanella MT, Ferreira SR (2003) Two-hour insulin determination improves the ability of abdominal fat measurement to identify risk for the metabolic syndrome. Diabetes Care 26:1725-1730

50. Smith SR, Zachwieja JJ (1999) Visceral adipose tissue: a critical review of intervention strategies. Int J Obes Relat Metab Disord 23:329-335

51. Boudou P, de Kerviler E, Erlich D, Vexiau P, Gautier JF (2001) Exercise training-induced triglyceride lowering negatively correlates with DHEA levels in men with type 2 diabetes. Int J Obes Relat Metab Disord 25:1108-1112
52. Lord J, Thomas R, Fox B, Acharya U, Wilkin T (2006) The effect of metformin on fat distribution and the metabolic syndrome in women with polycystic ovary syndrome-a randomised, double-blind, placebo-controlled trial. BJOG 113:817-824

53. Thorne A, Lonnqvist F, Apelman J, Hellers G, Arner P (2002) A pilot study of long-term effects of a novel obesity treatment: omentectomy in connection with adjustable gastric banding. Int $\mathrm{J}$ Obes Relat Metab Disord 26:193-199

54. Giese SY, Bulan EJ, Commons GW, Spear SL, Yanovski JA (2001) Improvements in cardiovascular risk profile with largevolume liposuction: a pilot study. Plast Reconstr Surg 108:510 519; discussion 20-21

55. Gonzalez-Ortiz M, Robles-Cervantes JA, Cardenas-Camarena L, Bustos-Saldana R, Martinez-Abundis E (2002) The effects of surgically removing subcutaneous fat on the metabolic profile and insulin sensitivity in obese women after large-volume liposuction treatment. Horm Metab Res 34:446-449

56. Cazes L, Deitel M, Levine RH (1996) Effect of abdominal lipectomy on lipid profile, glucose handling and blood pressure in patients with truncal obesity. Obes Surg 6:159-166

57. Klein S, Fontana L, Young VL et al (2004) Absence of an effect of liposuction on insulin action and risk factors for coronary heart disease. N Engl J Med 350:2549-2557

58. Matarasso A, Kim RW, Kral JG (1998) The impact of liposuction on body fat. Plast Reconstr Surg 102:1686-1689

59. Sjostrom L, Lindroos AK, Peltonen M et al (2004) Lifestyle, diabetes, and cardiovascular risk factors 10 years after bariatric surgery. N Engl J Med 351:2683-2693

60. Crossno JT Jr, Majka SM, Grazia T, Gill RG, Klemm DJ (2006) Rosiglitazone promotes development of a novel adipocyte population from bone marrow-derived circulating progenitor cells. J Clin Invest 116:3220-3228

61. Smith SR, Xie H, Baghian S et al (2006) Pioglitazone changes the distribution of adipocyte size in type 2 diabetics. Adipocytes 2:11-22

62. Ciaraldi TP, Kong AP, Chu NV et al (2002) Regulation of glucose transport and insulin signaling by troglitazone or metformin in adipose tissue of type 2 diabetic subjects. Diabetes 51:30-36

63. Lundgren M, Buren J, Ruge T, Myrnas T, Eriksson JW (2004) Glucocorticoids down-regulate glucose uptake capacity and insulin-signaling proteins in omental but not subcutaneous human adipocytes. J Clin Endocrinol Metab 89:2989-2997

64. Stolic M, Russell A, Hutley L et al (2002) Glucose uptake and insulin action in human adipose tissue-influence of BMI, anatomical depot and body fat distribution. Int $\mathrm{J}$ Obes Relat Metab Disord 26:17-23

65. Virtanen KA, Lonnroth P, Parkkola R et al (2002) Glucose uptake and perfusion in subcutaneous and visceral adipose tissue during insulin stimulation in nonobese and obese humans. J Clin Endocrinol Metab 87:3902-3910

66. Jensen MD, Sarr MG, Dumesic DA, Southorn PA, Levine JA (2003) Regional uptake of meal fatty acids in humans. Am J Physiol Endocrinol Metab 285:E1282-E1288

67. Marin P, Andersson B, Ottosson M et al (1992) The morphology and metabolism of intraabdominal adipose tissue in men. Metabolism 41:1242-1248

68. Fried SK, Russell CD, Grauso NL, Brolin RE (1993) Lipoprotein lipase regulation by insulin and glucocorticoid in subcutaneous and omental adipose tissues of obese women and men. J Clin Invest 92:2191-2198

69. Edens NK, Fried SK, Kral JG, Hirsch J, Leibel RL (1993) In vitro lipid synthesis in human adipose tissue from three abdominal sites. Am J Physiol 265:E374-E379 
70. Reynisdottir S, Dauzats M, Thorne A, Langin D (1997) Comparison of hormone-sensitive lipase activity in visceral and subcutaneous human adipose tissue. J Clin Endocrinol Metab 82:4162-4166

71. Van Harmelen V, Dicker A, Ryden M et al (2002) Increased lipolysis and decreased leptin production by human omental as compared with subcutaneous preadipocytes. Diabetes 51:2029-2036

72. Ramis JM, Salinas R, Garcia-Sanz JM, Moreiro J, Proenza AM, Llado I (2006) Depot- and gender-related differences in the lipolytic pathway of adipose tissue from severely obese patients. Cell Physiol Biochem 17:173-180

73. Van Harmelen V, Lonnqvist F, Thorne A et al (1997) Noradrenaline-induced lipolysis in isolated mesenteric, omental and subcutaneous adipocytes from obese subjects. Int $\mathrm{J}$ Obes Relat Metab Disord 21:972-979

74. Hellmer J, Marcus C, Sonnenfeld T, Arner P (1992) Mechanisms for differences in lipolysis between human subcutaneous and omental fat cells. J Clin Endocrinol Metab 75:15-20

75. Vikman HL, Savola JM, Raasmaja A, Ohisalo JJ (1996) Alpha 2A-adrenergic regulation of cyclic AMP accumulation and lipolysis in human omental and subcutaneous adipocytes. Int $\mathrm{J}$ Obes Relat Metab Disord 20:185-189

76. Mauriege P, Galitzky J, Berlan M, Lafontan M (1987) Heterogeneous distribution of beta and alpha-2 adrenoceptor binding sites in human fat cells from various fat deposits: functional consequences. Eur J Clin Invest 17:156-165

77. Bolinder J, Kager L, Ostman J, Arner P (1983) Differences at the receptor and postreceptor levels between human omental and subcutaneous adipose tissue in the action of insulin on lipolysis. Diabetes 32:117-123

78. Motoshima H, Wu X, Sinha MK et al (2002) Differential regulation of adiponectin secretion from cultured human omental and subcutaneous adipocytes: effects of insulin and rosiglitazone. J Clin Endocrinol Metab 87:5662-5667

79. Van Harmelen V, Reynisdottir S, Eriksson P et al (1998) Leptin secretion from subcutaneous and visceral adipose tissue in women. Diabetes 47:913-917

80. Bastelica D, Morange P, Berthet B et al (2002) Stromal cells are the main plasminogen activator inhibitor-1-producing cells in human fat: evidence of differences between visceral and subcutaneous deposits. Arterioscler Thromb Vasc Biol 22:173-178

81. Fried SK, Bunkin DA, Greenberg AS (1998) Omental and subcutaneous adipose tissues of obese subjects release interleukin-6: depot difference and regulation by glucocorticoid. J Clin Endocrinol Metab 83:847-850

82. Bruun JM, Lihn AS, Madan AK et al (2004) Higher production of IL-8 in visceral vs subcutaneous adipose tissue. Implication of nonadipose cells in adipose tissue. Am J Physiol Endocrinol Metab 286:E8-E13

83. Dusserre E, Moulin P, Vidal H (2000) Differences in mRNA expression of the proteins secreted by the adipocytes in human subcutaneous and visceral adipose tissues. Biochim Biophys Acta 1500:88-96

84. Van Harmelen V, Rohrig K, Hauner H (2004) Comparison of proliferation and differentiation capacity of human adipocyte precursor cells from the omental and subcutaneous adipose tissue depot of obese subjects. Metabolism 53:632-637
85. Shahparaki A, Grunder L, Sorisky A (2002) Comparison of human abdominal subcutaneous versus omental preadipocyte differentiation in primary culture. Metabolism 51:1211-1215

86. Tchkonia T, Giorgadze N, Pirtskhalava T et al (2002) Fat depot origin affects adipogenesis in primary cultured and cloned human preadipocytes. Am J Physiol Regul Integr Comp Physiol 282:R1286-R1296

87. Sewter CP, Blows F, Vidal-Puig A, O'Rahilly S (2002) Regional differences in the response of human pre-adipocytes to PPARgamma and RXRalpha agonists. Diabetes 51:718-723

88. Adams M, Montague CT, Prins JB et al (1997) Activators of peroxisome proliferator-activated receptor gamma have depotspecific effects on human preadipocyte differentiation. J Clin Invest 100:3149-3153

89. Rebuffe-Scrive M, Anderson B, Olbe L, Bjorntorp P (1990) Metabolism of adipose tissue in intraabdominal depots in severely obese men and women. Metabolism 39:1021-1025

90. Niesler CU, Prins JB, O'Rahilly S, Siddle K, Montague CT (2001) Adipose depot-specific expression of cIAP2 in human preadipocytes and modulation of expression by serum factors and TNFalpha. Int J Obes Relat Metab Disord 25:1027-1033

91. Li X, Chen R, Lindquist S, Hernell O (2004) Expression of cellular inhibitor of apoptosis protein-2 in human subcutaneous and omental adipose tissue. Int $\mathrm{J}$ Obes Relat Metab Disord $28: 352-356$

92. Joyner J, Hutley L, Cameron D (2002) Intrinsic regional differences in androgen receptors and dihydrotestosterone metabolism in human preadipocytes. Horm Metab Res 34:223-228

93. Belanger C, Hould FS, Lebel S, Biron S, Brochu G, Tchernof A (2006) Omental and subcutaneous adipose tissue steroid levels in obese men. Steroids 71:674-682

94. Bujalska IJ, Kumar S, Stewart PM (1997) Does central obesity reflect 'Cushing's disease of the omentum'? Lancet 349:1210 1213

95. Rebuffe-Scrive M, Bronnegard M, Nilsson A, Eldh J, Gustafsson JA, Bjorntorp P (1990) Steroid hormone receptors in human adipose tissues. J Clin Endocrinol Metab 71:1215-1219

96. Dumont M, Mauriege P, Bergeron J, Despres JP, Prud'homme D (2001) Effect of a six month gemfibrozil treatment and dietary recommendations on the metabolic risk profile of visceral obese men. Int J Obes Relat Metab Disord 25:1136-1143

97. Janand-Delenne B, Chagnaud C, Raccah D, Alessi MC, JuhanVague I, Vague P (1998) Visceral fat as a main determinant of plasminogen activator inhibitor 1 level in women. Int $\mathrm{J}$ Obes Relat Metab Disord 22:312-317

98. Kanai H, Tokunaga K, Fujioka S, Yamashita S, KamedaTakemura KK, Matsuzawa Y (1996) Decrease in intra-abdominal visceral fat may reduce blood pressure in obese hypertensive women. Hypertension 27:125-129

99. Miyatake N, Takahashi K, Wada J et al (2003) Daily exercise lowers blood pressure and reduces visceral adipose tissue areas in overweight Japanese men. Diabetes Res Clin Pract 62:149 157

100. Okura T, Nakata Y, Yamabuki K, Tanaka K (2004) Regional body composition changes exhibit opposing effects on coronary heart disease risk factors. Arterioscler Thromb Vasc Biol 24:923-929 